\title{
Experimental Investigation on Endurance Test of Turbofan Engine
}

\author{
Yao Huating ${ }^{1}$, Jia Linyuan ${ }^{2} \&$ Wang $\mathrm{Xi}^{1}$ \\ ${ }^{1}$ Beijing University of Aeronautics and Astronautics, Beijing, China \\ ${ }^{2}$ School of Power and Energy, Northwestern Polytechnical University, Xi' an, China \\ Correspondence: Jia Linyuan, School of Power and Energy, Northwestern Polytechnical University, Xi'an \\ 710072, Shaanxi, China. Tel: 86-29-8849-2043. E-mail: dearjulian@mail.nwpu.edu.cn
}

Received: March 20, 2012 Accepted: June 18, 2012 Online Published: June 20, 2012

doi:10.5539/mas.v6n7p43 URL: http://dx.doi.org/10.5539/mas.v6n7p43

\begin{abstract}
In this test, we accumulate more than 10 hours of high-thrust state durability test on a turbofan engine. The test is conducted on a directly connected tube test cell which can simulate different flight altitudes and flight speeds. Performance parameters and important cross-section parameters are collected and the engine is decomposed after the test. The law of engine performance degradation caused by the aging of the engine parts performance is summarized based on the changes of performance parameters, important cross-section parameters and the structure of engine. Engine air path fault diagnosis is conducted using some test data to give approximate value of some component performance deterioration. The method and theoretic analysis are of some engineering value.
\end{abstract}

Keywords: turbofan engine, durability test, engine performance deterioration, fault diagnosis

\section{Introduction}

During the whole life of a turbofan engine, engine components always suffer pollutions, distortions and erosions, etc. These components deterioration usually result in performance loss of the engine, such as thrust lose and specific fuel consumption increase, etc. But this doesn't mean that this engine cannot be safely used anymore. So it is of great importance to know the reason and ways of how engine performance varying reflects the unmeasurable components deterioration. Ma (1990) and Ye (1993) analyzed some corresponding problems on big-thrust long-life turbofan engines, but no researches involved in small-thrust short-life engines are found by now.

The test has been done with an intact short-life turbofan engine. According to its design usage conditions, a turbofan engine endurance test is carried out for more than ten hours. After the test, the engine is disassembled, lots of data are gathered and the ways of performance varying are obtained and theoretically analyzed. This study can provide some evidence for safe usage of the engine. Fan $(1990 ; 1994)$ and Sun $(2010)$ has developed some linear fault diagnosis models for gas turbine engine. These models are employed to the corresponding engine to validate the theoretic analysis of the engine performance deterioration. Also the degree of component performance deterioration is calculated approximatively to give some principles on safe usage of the engine.

\section{Test Methods}

\subsection{Test Devices}

The test facility is a connected tube test cell, which is shown in Figure 1. With the air flow pressed and heated, the turbofan engine ground test facility can simulate the engine inlet total temperature $T_{\mathrm{t} 1}$ and total pressure $P_{\mathrm{t} 1}$ under following conditions: sea level, ISA, Mach number $0.0 \sim 0.8$ and inlet total pressure loss coefficient $0.90 \sim 1.0$. 


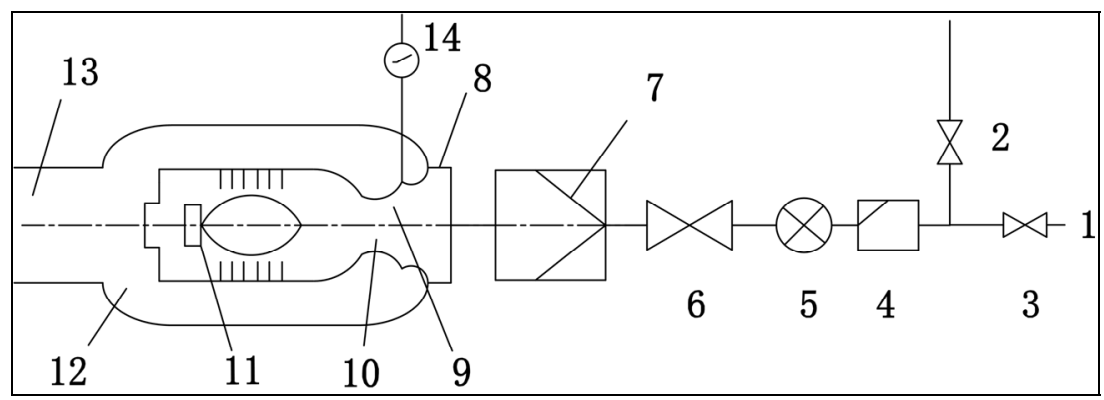

Figure 1. Sketch of connected tube test cell

1-Compressed air; 2-Electromotion valve (to atmosphere); 3-Electromotion valve;

4-Fast valve; 5-Pressure valve; 6- Electro motion valve; 7-Air heater; 8-Steady section;

9-Test section; 10-'S' type air inlet; 11-Small turbofan engine; 12-High altitude cabin;

13-Exaust system; 14-'Buterfly’ valve (to atmosphere).

\subsection{Test Parameters}

Measured parameters consist of section parameters and performance parameters. However it is impossible to measure parameters of all the engine sections. Hence, some key sections are selected and parameters of these sections are measured. Given the fact that the temperature at the entrance of gas turbine is extremely high, the temperature at the exit instead of that at the entrance of gas turbine is measured, though the gas turbine entrance is a key section theoretically. But the total temperature at gas turbine entrance is reflected by the gas generator exhaust temperature at the exit of gas turbine. Performance parameters are chosen as those like engine thrust, fuel mass flow and rotating speed.

(1) Section parameters: Flow parameters, namely, temperature, pressure and velocity of each section including ambient conditions, engine inlet section, and key sections within engine flow path, such as fan outlet, high pressure compressor outlet, and gas turbine outlet.

(2) Performance parameters: namely engine thrust, rotating speed of high pressure spool and low pressure spool, and fuel mass flow.

\subsection{Test Methods}

The endurance test is carried out at intervals of two hours after each time the measured parameters are initialed and test conducted, while the engine is fixed on the test bed during that time. Except acceleration, deceleration and some throttle ratings, the engine mainly performed at maximum rating or $95 \%$ of maximum rating to accelerate aging.

\subsection{Test Sequence (Serial Numbers) and Engine Operating Time}

The engine endurance test is carried out for 8 phases of which the total test time adds up to approximate 10 hours. The engine operating states and operating time of each phase are provided in Table 1.

Table 1. Serial numbers and operating state and time

\begin{tabular}{ccc}
\hline Serial numbers & Engine thrust & Operating time continuously \\
\hline 1 (state 1) & $1.00 F_{\max }$ & 18 minutes \\
2 (state 2) & $0.95 F_{\max }$ & 76 minutes \\
3 (state 3) & $1.00 F_{\max }$ & 85 minutes \\
4 (state 4) & $0.95 F_{\max }$ & 77 minutes \\
5 (state 5) & $1.00 F_{\max }$ & 83 minutes \\
6 (state 6) & $0.95 F_{\max }$ & 85 minutes \\
7 (state 7) & $1.00 F_{\max }$ & 112 minutes \\
8 (state 8$)$ & $1.00 F_{\max }$ & 92 minutes \\
\hline Sum & - & 628 minutes \\
\hline
\end{tabular}

Note: $F_{\max }$ is the thrust at maximum rating 


\subsection{Examinations after the Engine Disassembled}

By examining the disassembled engine, some crack, distortions and erosions have been found on inlet guide vanes of gas turbine. An increase of the throat area of gas turbine guide vanes $\left(A_{\mathrm{nb}}\right)$ has been detected by measurement. Learned from experiences, under this condition, the engine wouldn't be in deadly danger. Abnormality is not found within other engine components.

\section{Results and Analysis}

\subsection{Analysis of Variation of Measured Parameters}

With comparison of state 1 (brand new state engine), state 5 (engine has operated 339 minutes consecutively) and state 8 (engine has operated 628 minutes consecutively), which are three typical test states, the law and magnitude of primary parameters varying with the operating time could be obtained. Then, the test parameters varying (relative value) during a throttle state are analyzed and some results are discussed infra.

\subsubsection{Variation of Gas Turbine Outlet Temperature}

With the rotating speed (relative value $n_{\mathrm{h}}=1.0$ ) of high pressure spool fixed, engine operated from state 1 to state 5 , then to state 8 , the total temperature of gas turbine outlet, namely $T_{t 5}$, has increased by $1.5 \%$ and $1.8 \%$ respectively, as is shown in Figure 2.

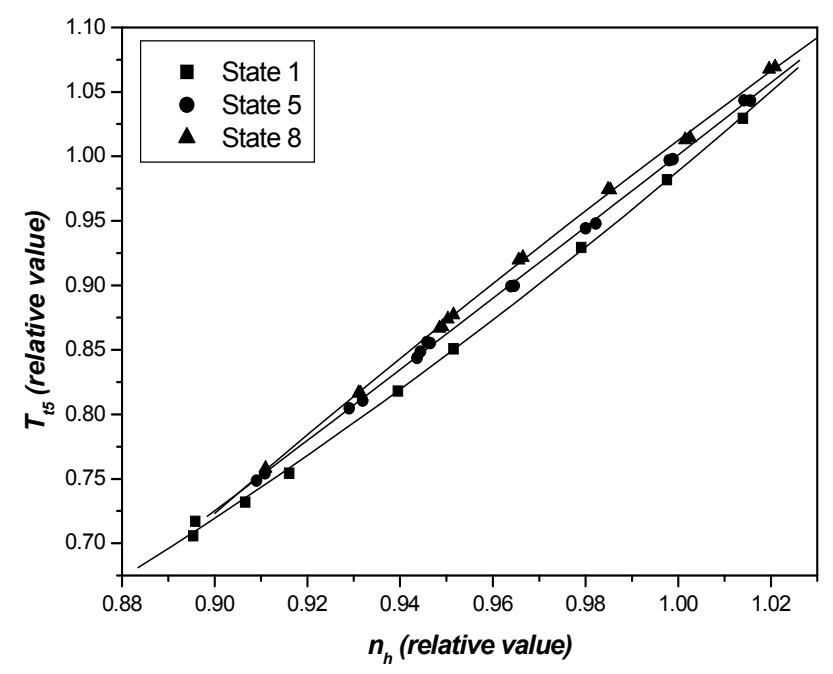

Figure 2. Variation of $\mathrm{T}_{\mathrm{t} 5}$

The reason is as follows. When the low pressure turbine is under critical or supercritical conditions, employing the mass conservation equation between gas turbine and low pressure turbine (Lian \& Wu, 2005):

$$
\pi_{T, h}=\left(\text { Const } \times \frac{A_{n b, l}}{A_{n b, h}}\right)^{\frac{2 k}{k+1}}
$$

$\pi_{T, h}$ - pressure ratio of gas turbine

$A_{n b, h}$ - gas turbine throat area

$A_{n b, l}$ - low pressure turbine throat area

$k$ - ratio of specific heat

Const -constant value

With low pressure turbine throat area fixed, pressure ratio of gas turbine will decrease as gas turbine throat area increases. On the other hand, according to the law of energy conservation between compressor and gas turbine:

$$
L_{k}=L_{T}=C_{P} T_{t 4}\left(1-\frac{1}{\pi_{T, h}^{\frac{k-1}{k}}}\right) \eta_{T, h}
$$

$L_{k}$ - compressor power 
$L_{T}$ - gas turbine power

$C_{p}$ - constant-pressure specific heat

$T_{\mathrm{t} 4}$ - gas turbine inlet temperature

$\eta_{T, h}$ - gas turbine efficiency

Regardless of variation of gas turbine efficiency and compressor efficiency (namely compressor power is constant), the gas turbine power will be constant. To retain constant gas turbine power, the gas turbine inlet temperature increases with the decrease of gas turbine pressure ratio. Consequently, the gas turbine outlet temperature increases correspondingly. During the endurance test, the apparent increase of $T_{t 5}$, in fact, is a reflection of the gas turbine throat area increase caused by distortions and erosions. The increase of gas turbine outlet temperature at state 5 and state 8 are, respectively, identical with the fact of increase of gas turbine throat area.

The increase of gas turbine throat area can also be seen and reflected by the variation tendency of gas turbine pressure ratio (see Figure 3), which tends to descend at the same relative rotating speed of high pressure spool. Reasons can be seen in the mass conservation equation between compressor and gas turbine (Lian \& Wu, 2005):

$$
\frac{\pi_{C}}{q(\lambda)}=\text { Const } \times \frac{1}{A_{n b, h}} \sqrt{\frac{T_{t 4}}{T_{t 1}}}
$$

$\pi_{C}$ - compressor pressure ratio

$q(\lambda)$ - mass flow function at compressor entrance

$T_{t 1}$ - total temperature at compressor entrance

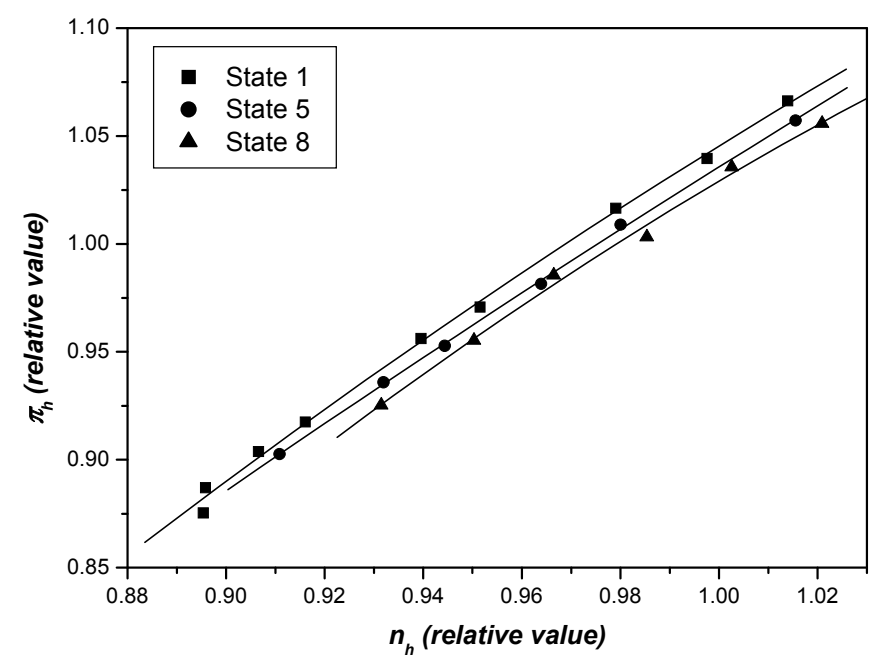

Figure 3. Variation of $\pi_{h}$

When gas turbine throat area increases, the ratio $\pi_{\mathrm{C}} / q(\lambda)$ would decrease, which results in decreasing of compressor pressure ratio, whereas high pressure compressor mass flow function $q(\lambda)$ increases. So compressor working point tends to move away from stall margin. Meanwhile, engine bypass ratio decreases a little with the increase of mass flow through gas generator (Niekayefu, 1999).

\subsubsection{Fan Operation State}

Caused by the increase of mass flow function of compressor, fan pressure ratio decreases a little. Nevertheless, the mass flow function of fan is smaller than that of the compressor due to the fact that there is no change in bypass mass flow. Namely, the decrease of fan pressure ratio is smaller than that of compressor (Figure 4). The variation in rotating speed of low pressure spool depends on the variation in the power of low pressure turbine. However, the degree of temperature increase is lower than the pressure ratio decrease; which results in the little decrease (smaller than 1\%, showed in Figure 5) of rotating speed of low pressure spool. So there is little change in fan operation state. 


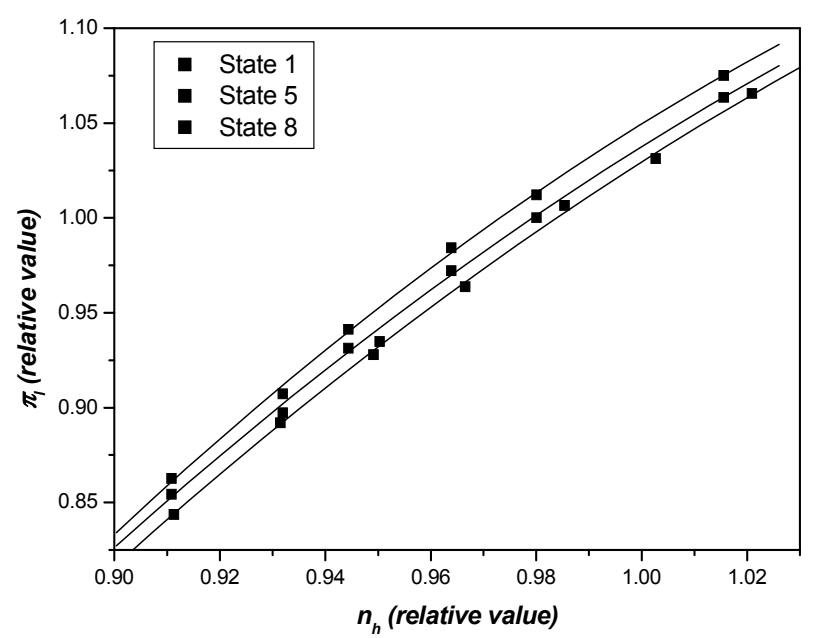

Figure 4. Variation of $\pi_{1}$

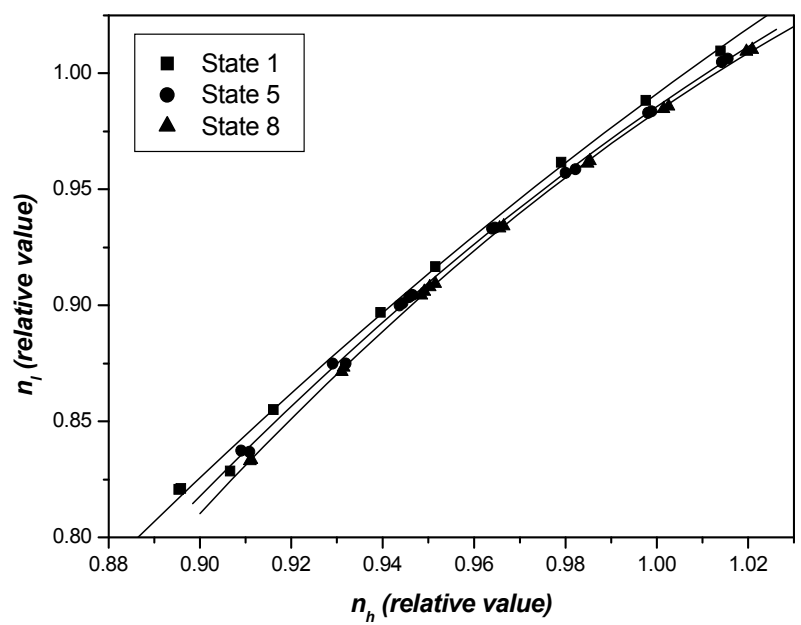

Figure 5. Variation of $n_{1}$

\subsubsection{Variation in Thrust}

Figure. 6 shows the variation in thrust for the engine operating from state 1 to state 5 , then to state 8 , with the rotating speed of high pressure spool fixed $\left(n_{\mathrm{h}}=1.0\right)$. The engine thrust decreases by $1.3 \%$ and $3 \%$, respectively. Lots of factors contribute to the variation in engine thrust.

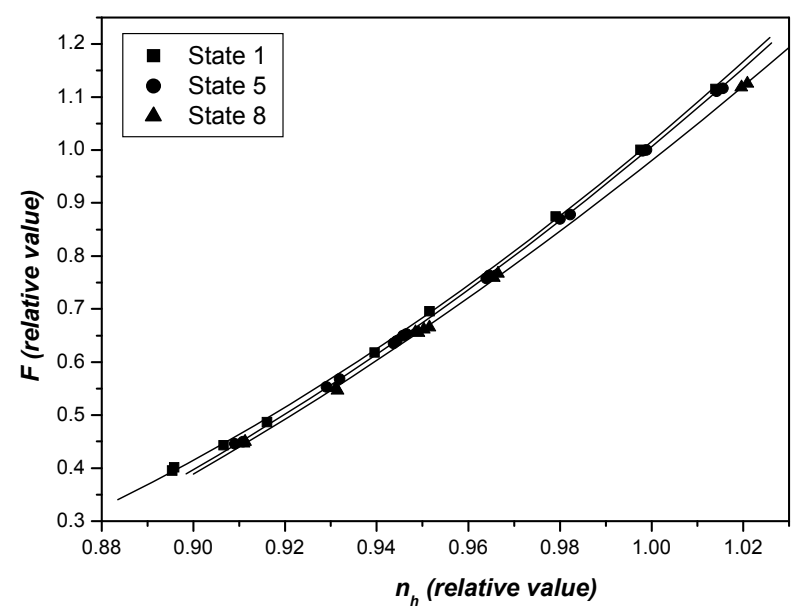

Figure 6. Variation of $F_{n}$ 
The relations between other parameters and engine thrust are listed in Table 2.

Table 2. Engine thrust factors

\begin{tabular}{lll}
\hline $\begin{array}{c}\text { Variation in } \\
\text { factors }\end{array}$ & $\begin{array}{c}\text { Variation } \\
\text { in thrust }\end{array}$ & \multicolumn{1}{c}{ Reason analysis } \\
\hline$T_{\mathrm{t} 5}$ increase & increase & $\begin{array}{l}\text { Gas turbine inlet temperature increase, nozzle exhaust } \\
\text { velocity increase. }\end{array}$ \\
$\begin{array}{l}\text { Core mass flow } \\
\text { increase }\end{array}$ & increase & $\begin{array}{l}\text { Bypass ratio decrease, core thrust increase more than } \\
\text { bypass thrust decrease. }\end{array}$ \\
$\pi_{\mathrm{T}}$ decrease & decrease & $\begin{array}{l}\text { Gas turbine efficiency decrease. } \\
\pi_{\mathrm{h}} \text { decrease }\end{array}$ \\
decrease & $\begin{array}{l}\text { High pressure compressor efficiency decrease, total } \\
\text { pressure ratio decrease, thermal efficiency decrease. }\end{array}$ \\
$\pi_{\mathrm{l}}$ decrease & decrease & $\begin{array}{l}\text { Fan efficiency decrease, total pressure ratio decrease, } \\
\text { thermal efficiency decrease. }\end{array}$ \\
\hline
\end{tabular}

\subsubsection{Variation in Specific Fuel Consumption}

The variation in specific fuel consumption can be seen in Figure 7. The decrease of thrust combining with the increase of fuel consumption caused the increase of specific fuel consumption. Likewise, the increase of specific fuel consumption can also be analyzed according to components deterioration.

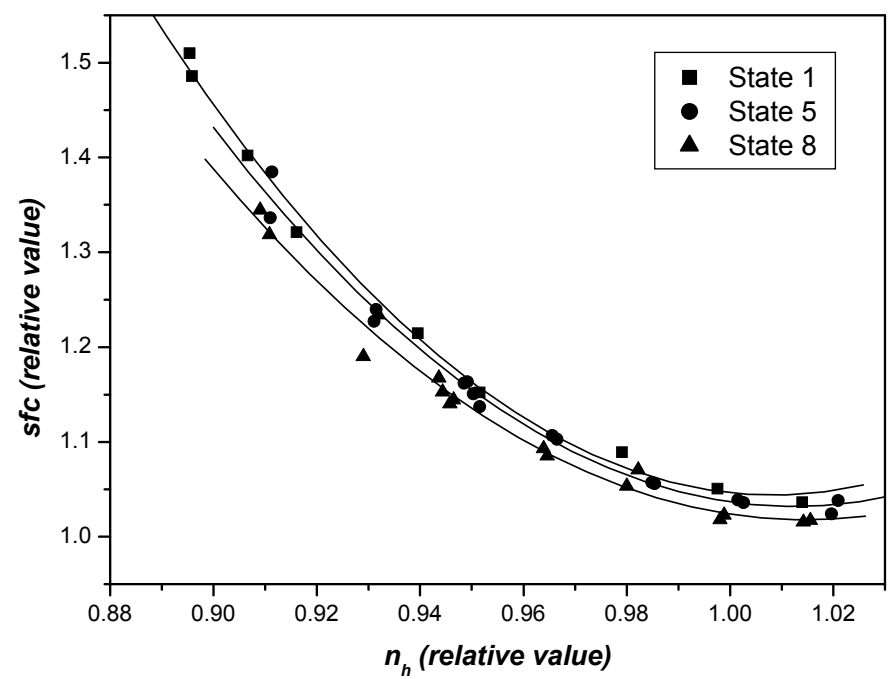

Figure 7. Variation of $s f c$

\subsection{Linear Fault Diagnosis}

To validate the influence of components parameters on engine performance, a linear fault diagnosis model is built for the corresponding engine. Engine fault diagnosis equations have fault factors as independent variables and measured parameters as responses. The equations can be rewritten in terms of matrix as follows:

$$
\delta y=A \delta x+e
$$

In equation (4), $\delta y$ is an $m \times 1$ vector stands for the offset of measured parameters; $\delta x$ is an $n \times 1$ vector stands for the offset of engine state parameters; $e$ is an $m \times 1$ vector stands for stochastic errs; $A$ is an $m \times n$ matrix stands for the influence coefficient matrix.

The process of fault diagnosis is to calculate elements of $\delta x$ with $\delta y$ and $A$ given, by solving equation (4). $\delta x$ stands for the type of engine fault, whereas $\delta x_{j}(j=1,2, \cdots, n)$ stands for the degree of that fault. 
The selection of measured parameters (or the so called response parameters) is largely dependent on the measurement condition during engine test and usage. On one hand they should reflect the changes of engine performance parameters; on the other hand the relativity of different parameters should be as little as possible. The corresponding engine is located in the test cell, thus, the measurement condition is limited. Hence, measured parameters are selected as follows: the rotating speed of low speed rotor $n_{l}$, engine thrust $F_{n}$, specific fuel consumption $S F C$ and gas generator exhaust gas temperature $T_{\mathrm{t} 5}$.

The selection of fault factors depends on the structure and working conditions of the engine. In the model of twin-spool turbofan engine fault diagnosis, twelve fault factors are selected as follows: corrected fan mass flow WAFC, fan efficiency ETAF, corrected compressor mass flow WACC, compressor efficiency ETAC, relative pressure loss in combustor DPCOM, combustion efficiency ETAB, corrected gas turbine mass flow TFFHP, gas turbine efficiency ETATHP, corrected low pressure turbine mass flow TFFLP, low pressure turbine efficiency ETATLP, area of core exhaust nozzle A8, area of duct exhaust nozzle A8D.

The first step of fault diagnosis is to obtain the influence coefficient matrix (or the small deviation matrix) by adding a small err to each fault factor and calculating the relative changes of measured parameters. The influence coefficient matrix of the corresponding engine is shown in Table 3. Each column stands for relative changes of measured parameters when the fault factor is changed by $1 \%$.

Table 3. Influence coefficient matrix

\begin{tabular}{|c|c|c|c|c|c|c|}
\hline & WAFC & ETAF & WACC & ETAC & DPCOM & ETAB \\
\hline$n_{1}$ & -0.7675 & 0.7413 & 0.6282 & -0.8677 & 0.0477 & 0.0011 \\
\hline$T_{t 5}$ & -0.0015 & 0.0477 & 1.5959 & -0.4776 & 0.4107 & -0.006 \\
\hline SFC & 0.5788 & 0.2853 & 1.1466 & 0.0191 & 0.3156 & 0.9572 \\
\hline \multirow[t]{2}{*}{$F_{n}$} & -1.377 & -0.5305 & 1.7389 & -2.0263 & 0.2542 & 0.015 \\
\hline & TFFHP & ЕТАТНР & TFFLP & ETATLP & A8 & A8D \\
\hline $\mathbf{n}_{1}$ & 0.708 & -0.4876 & 0.4854 & -1.3135 & -0.6134 & -0.1503 \\
\hline$T_{\mathrm{t} 5}$ & 1.7929 & 0.275 & 0.8839 & -0.9507 & 0.3467 & -0.0115 \\
\hline$S F C$ & 1.2997 & 0.6016 & 0.5798 & 0.0368 & 0.324 & 0.0773 \\
\hline$F_{n}$ & 1.9416 & -0.7476 & 1.2412 & -2.8825 & -0.5106 & 0.1006 \\
\hline
\end{tabular}

When the influence coefficient matrix is ready, engine fault diagnosis can be conducted using relative changes of measured parameters based on test data. Choosing test data of state 5 and state 8 as engine fault samples, and the corresponding relative changes of measured parameters are as follows:

$$
\begin{aligned}
& \delta\left(n_{l}, T_{\mathrm{t} 5}, S F C, F_{n}\right)_{5}=(-0.00385,0.01637,-0.00687,-0.00839) \\
& \delta\left(n_{l}, T_{\mathrm{t} 5}, S F C, F_{n}\right)_{8}=(-0.00631,0.02843,-0.02153,-0.02609)
\end{aligned}
$$

Equation (4) offers a way of calculating $\delta x$ or obtaining the solution of fault diagnosis. Until recently the most effective way of solving equation (4) is a method called primary factor model. Considering the limitation that there are only 4 measured parameters, the fault diagnosis could only be conducted with 4 fault factors. Different combination of fault factors are called engine fault mode. Hence, there will be $C_{12}^{4}=495$ engine fault modes. Should every fault be considered, there will be massive work to be done. Thus, the so called similarity coefficient method for engine air path fault diagnosis is employed (Chen \& Huang, 2010).

Given two vectors $X, Y$, their similarity coefficient $R_{X, Y}$ is defined as:

$$
R_{X, Y}=\frac{\operatorname{Cov}(X, Y)}{\sqrt{\operatorname{Var}(X) \operatorname{Var}(Y)}}
$$

$\operatorname{Cov}(X, Y)$ - Covariance of vector $\mathrm{X}$ and vector $\mathrm{Y}$;

$\operatorname{Var}(X)$ - Variance of vector $\mathrm{X}$.

Similarity coefficient reflects the similarity of two vectors. Obviously, $\left|R_{X, Y}\right| \leq 1$, and while $\left|R_{X, Y}\right|$ reaches 1.0, vector $X, Y$ get higher similarity. 
With the similarity coefficients of every column of influence coefficient matrix to err vectors of measured parameters calculated, fault factors are selected reasonably. Calculation works can be simplified and the multicollinearity of the fault equations will be lower, because the disadvantage of calculation of every possible combination of fault factors is overcome. Definition of similarity coefficient is given and similarity coefficient of some fault diagnosis is calculated.

With the similarity coefficient method for the selection of primary fault factors, the similarity coefficient of fault factors is calculated (see Table 4).

Table 4. Engine fault factor and similarity coefficients

\begin{tabular}{|c|c|c|c|c|c|c|c|}
\hline \multicolumn{2}{|c|}{ fault factors } & ETAF & WAFC & ETAC & WACC & DPCOM & ETAB \\
\hline \multirow{2}{*}{$\begin{array}{l}\text { similarity } \\
\text { coefficient }\end{array}$} & state 5 & 0.3181 & 0.0432 & 0.2736 & 0.3351 & 0.5538 & -0.3724 \\
\hline & state 8 & -0.5771 & -0.9697 & 0.8963 & -0.7656 & 0.3948 & -0.4077 \\
\hline \multicolumn{2}{|c|}{ fault factors } & ETATHP & ETATLP & TFFHP & TFFLP & A8 & A8D \\
\hline \multirow{2}{*}{$\begin{array}{l}\text { similarity } \\
\text { coefficient }\end{array}$} & state 5 & 0.2771 & 0.3780 & 0.9670 & 0.2367 & 0.5443 & -0.2478 \\
\hline & state 8 & 0.8903 & -0.4545 & 0.9997 & -0.7805 & -0.1583 & 0.6388 \\
\hline
\end{tabular}

According to the theory of similarity coefficient method, fault factors with bigger similarity coefficients are more likely to be the real engine faults. Although the similarity coefficient of ETAC reaches 0.8963 , it is not selected in the fault mode, because according to some conclusions made by Fan Z. M. (1993; 1997), ETAC and ETATHP are highly collinearly. Meanwhile, considering the fact that there are distortions and erosions of turbine throat after the disassembly of engine, the faults are most possibly to occur at gas turbine. So, three groups fault modes are selected and the diagnosing results of two fault points are as follows:

Table 5. Diagnosing results of different fault modes

\begin{tabular}{ccc}
\hline fault modes & fault samples & solutions to fault diagnostics \\
\hline \multirow{2}{*}{ (WAFC, ETATHP, TFFHP, TFFLP) } & state 5 & $(-0.0013,0.2537,-0.575,-0.0736)$ \\
& state 8 & $(0.0017,0.5593,-1.2812,-0.1662)$ \\
(ETATHP, ETATLP, TFFHP, TFFLP) & state 5 & $(0.2434,0.0200,-0.5729,-0.0850)$ \\
& state 8 & $(0.5726,-0.0259,-1.284,-0.1515)$ \\
(ETAF, ETATHP, TFFHP, TFFLP) & state 5 & $(0.0211,0.2525,-0.5930,-0.0925)$ \\
& state 8 & $(-0.0273,0.5609,-1.258,-0.1419)$ \\
\hline
\end{tabular}

As is shown in Table 5, the main engine faults are the decrease of high turbine efficiency and the increase of gas turbine throat area. Comparison of the two fault samples shows that there are some inheritances and developments of engine faults from state 5 to state 8 . For example, under state 5 , the gas turbine efficiency go down about $0.2434 \% \sim 0.2537 \%$, while under state 8 , the decreasing value reaches $0.56 \% \sim 0.57 \%$; under state 5 , the throat area of gas turbine increases about $0.5729 \% \sim 0.5930 \%$, while under state 8 , the value arrives at $1.26 \% \sim 1.28 \%$. This is about the same of the observed distortions of real turbine components after the disassembly.

Fault diagnosis stated above is pertinent to ground maximum state, hence the result only illuminate the component performance deterioration at maximum rating. However degree of engine components performance deterioration differs under different working conditions, so it is necessary to conduct fault diagnosis under 'all working conditions'. In practice, fault diagnoses under some more working conditions are employed instead of 'all working conditions'. In this paper, fault diagnoses under rotating speed of $90 \%$ and $95 \%$ are conducted; also 
state 5 and state 8 are selected as fault samples. The influence coefficient matrixes are given in Table 6 and Table 7.

Table 6. Influence coefficient matrix at $95 \%$ rotating speed

\begin{tabular}{|c|c|c|c|c|c|c|}
\hline & WAFC & ETAF & WACC & ETAC & DPCOM & ETAB \\
\hline$n_{l}$ & 0.6072 & -0.72 & -0.8127 & 0.6857 & 0.09 & $5 \mathrm{E}-4$ \\
\hline$T_{\mathrm{t} 5}$ & 0.0431 & 0.0174 & -0.4212 & 1.5281 & 0.4456 & -0.0079 \\
\hline$S F C$ & 0.211 & 0.5887 & 0.0461 & 0.9468 & 0.3304 & 0.9573 \\
\hline \multirow[t]{2}{*}{$F_{n}$} & -0.0395 & 0.0228 & 0.0218 & -0.0439 & -0.0116 & -0.0024 \\
\hline & TFFHP & ЕТАТНР & TFFLP & ETATLP & A8 & A8D \\
\hline$n_{l}$ & 0.5102 & 0.773 & -1.3423 & -0.4659 & -0.5466 & -0.0357 \\
\hline$T_{\mathrm{t} 5}$ & 0.8596 & 1.6894 & -0.9242 & 0.2817 & 0.3261 & -0.0224 \\
\hline$S F C$ & 0.4798 & 1.0391 & 0.0991 & 0.6133 & 0.2808 & -0.0033 \\
\hline$F_{n}$ & -1.115 & -0.1658 & 1.0177 & -0.0891 & -0.1017 & 0.0101 \\
\hline
\end{tabular}

Table 7. Influence coefficient matrix at $90 \%$ rotating speed

\begin{tabular}{ccccccc}
\hline & WAFC & ETAF & WACC & ETAC & DPCOM & ETAB \\
\hline $\boldsymbol{n}_{\boldsymbol{l}}$ & 0.1821 & -0.5663 & -0.4459 & 0.5999 & -0.0066 & $9 \mathrm{E}-4$ \\
$\boldsymbol{T}_{\mathbf{t} 5}$ & 0.0268 & 0.0166 & -0.0472 & 1.1868 & 0.1209 & -0.0123 \\
$\boldsymbol{S F C}$ & 0.2818 & 0.62 & 0.3304 & 0.6726 & 0.1256 & 0.9598 \\
$\boldsymbol{F}_{\boldsymbol{n}}$ & -0.5096 & -1.1949 & -1.3837 & 1.8074 & -0.029 & 0.0097 \\
\hline & & & & & & \\
\hline & $\mathbf{T F F H P}$ & $\mathbf{E T A T H P}$ & $\mathbf{T F F L P}$ & $\mathbf{E T A T L P}$ & $\mathbf{A 8}$ & $\mathbf{A 8 D}$ \\
\hline $\boldsymbol{n}_{\boldsymbol{l}}$ & 0.5494 & 0.702 & -0.3592 & -1.0659 & -0.3746 & 0.1136 \\
$\boldsymbol{T}_{\mathbf{t}}$ & 0.9325 & 1.3721 & 0.1604 & -0.7938 & 0.1665 & -0.0459 \\
$\boldsymbol{S} \boldsymbol{F C}$ & 0.4687 & 0.769 & 0.637 & 0.3348 & 0.2275 & -0.0126 \\
$\boldsymbol{F}_{\boldsymbol{n}}$ & 1.6502 & 2.1187 & -0.5631 & -2.3584 & -0.1552 & 0.1483 \\
\hline
\end{tabular}

The method of similarity coefficient is employed to select fault factors. This method has been introduced before and the similarity coefficients are not supposed to be given here. But the results of fault diagnoses are given and some necessary theoretic analyses are enumerated.

State 5 and state 8 are selected as fault samples at $95 \%$ rotating speed, they are given as follows:

$$
\begin{aligned}
& \delta\left(n_{l}, T_{\mathrm{t} 5}, S F C, F_{n}\right)_{5}=(-0.00425,0.01918,-0.00713,-0.01347) \\
& \delta\left(n_{l}, T_{\mathrm{t} 5}, S F C, F_{n}\right)_{8}=(-0.00779,0.03128,-0.02387,-0.03275)
\end{aligned}
$$

Fault samples are taken into equation (4) to solve the fault equation. Results of fault diagnosis at $95 \%$ rotating speed are shown in Table 8 . 
Table 8. Diagnosis results of different fault modes at $95 \%$ rotating speed

\begin{tabular}{ccc}
\hline fault modes & fault samples & solutions to fault diagnostics \\
\hline \multirow{2}{*}{ (WAFC, ETATHP, TFFHP, TFFLP) } & state 5 & $(-0.0112,0.2787,-0.599,-0.0692)$ \\
& state 8 & $(-0.0226,0.5783,-1.261,-0.1507)$ \\
(ETAF, ETATHP, TFFHP, TFFLP) & state 5 & $(-0.0790,0.2712,-0.614,-0.0960)$ \\
& state 8 & $(-0.1595,0.5634,-1.291,-0.2048)$ \\
\hline
\end{tabular}

As is shown in Table 8, the gas turbine efficiency go down about $0.2712 \% \sim 0.2787 \%$ under state 5 , while the decreasing value reaches $0.5634 \% \sim 0.5783 \%$ under state 8 ; under state 5 , the throat area of gas turbine increases about $0.599 \% \sim 0.614 \%$, while under state 8 , the value reaches $1.261 \% \sim 1.291 \%$. Comparison of data in Table 8 and Table 5 illuminates that results of fault diagnoses at $95 \%$ rotating speed is similar to that at maximum rotating speed, because a difference of $5 \%$ rotating speed does not change the degree of component performance deterioration.

Also state 5 and state 8 are selected as fault samples at $90 \%$ rotating speed, they are given as follows:

$$
\begin{aligned}
& \delta\left(n_{l}, T_{\mathrm{t}}, S F C, F_{n}\right)_{5}=(-0.00425,0.01918,-0.00713,-0.01347) \\
& \delta\left(n_{l}, T_{\mathrm{t} 5}, S F C, F_{n}\right)_{8}=(-0.00779,0.03128,-0.02387,-0.03275)
\end{aligned}
$$

Fault samples are taken into equation (4) to solve the fault equation. Results of fault diagnosis at $90 \%$ rotating speed are shown in Table 9.

Table 9. Diagnosis results of different fault modes at $90 \%$ rotating speed

\begin{tabular}{ccc}
\hline fault modes & fault samples & solutions to fault diagnostics \\
\hline \multirow{2}{*}{ (WAFC, ETATHP, TFFHP, TFFLP) } & state 5 & $(-0.0481,0.5997,-0.931,-0.0839)$ \\
& state 8 & $(-0.1095,1.0646,-1.667,-0.1592)$ \\
(ETAF, ETATHP, TFFHP, TFFLP) & state 5 & $(-0.2123,0.5650,-0.7561,0.1042)$ \\
& state 8 & $(-0.4834,0.9855,-1.2695,0.2690)$ \\
\hline
\end{tabular}

As is shown in Table 9, the gas turbine efficiency go down about $0.5650 \% \sim 0.5997 \%$ under state 5 , while the decreasing value reaches $0.9855 \% \sim 1.0646 \%$ under state 8 ; under state 5 , the throat area of gas turbine increases about $0.7561 \% \sim 0.931 \%$, while under state 8 , the value reaches $1.2695 \% \sim 1.667 \%$. Comparison of data in Table 9 and Table 5 illuminates that results of fault diagnoses at $90 \%$ rotating speed differ from that at maximum rotating speed. Firstly, fault diagnosis results of gas turbine throat area differ a little due to some accuracy problems about the fault diagnosis model because the area ought to stay steady under different working conditions. Secondly, the reduction of gas turbine efficiency doubled at $90 \%$ rotating speed, which illustrate that engine component performance deterioration differs under different working conditions.

\section{Conclusions}

(1) Performing at maximum rating or near maximum rating for long time can accelerate the aging of short-life turbofan engine significantly.

(2) During the endurance test, the gas turbine outlet temperature apparently increases, which indicates the gas turbine throat area increase caused by distortions and erosions. However, the engine can still perform safely if the temperature increase didn't hit the limitation.

(3) Compressor operation state, engine thrust and specific fuel consumption are apparently affected by the increase of gas turbine throat area which, however, has little effect on the fan operation point and the stability of engine. 
(4) With the engine fault diagnostics techniques employed, it is found that erosions of gas turbine throat caused the decrease in efficiency and increase of flow capability, which caused engine performance variation. Meanwhile, the technique can present the approximate ranges of component performance variations.

(5) Engine components performance deterioration varies under different ratings, so it is necessary to do fault diagnosis under 'all engine ratings'.

\section{References}

Chen, Y. Ch., \& Huang, X. L. H. (2010). Similar Coefficients Method of Primary Factors Selection for Aero engine Fault Diagnosis. Aero nautical Computing Technique, 40(6), 55-57.

Fan, Z. M. F., \& Sun, Ch. L. (1990). Formation and Solution of Engine Fault Equations. Journal of Civil Aviation Institute of China, 8(4), 1-13.

Fan, Z. M. (1993). Primary Factor Model for Jet Engine FaultDiagnosis. Acta Aeronautica Et Astronautica Sinica, 14(12), 588-595.

Fan, Z. M., \& Sun, Ch. L. (1994). Development of Engine Fault Equation and Introduction of Fault Factors. Journal of Civil Aviation Institute of China, 12(1), 1-14.

Fan, Z. M. (1997). A Study on the Fault Correlation Criterion for Jet Engine Diagnosis. Journal of Civil Aviation Institute of China, 15(4), 1-8.

Lian, X. Ch., \& Wu, H. (2005). Principles for Aero Gas Turbine Engine. Xi'an: Northwestern Polytechnical University Press.

Ma, H. Zh. (1990). Performance design and testing of turbofan engine WS6. International Aviation, No. 10, 56-58.

Sun, X. F., \& Chen, Y. Ch. (2010). Research on selection of measurement parameters of engine fault diagnosis based on primary factor model. Journal of Aerospace Power, 25(1), 129-135.

Ye, Z. D., \& Guo, Zh. M. (1993). Performance testing of a turbofan engine. Journal of Engineering for Thermal Energy and Power, 8(3), 130-133.

Niekayefu, Ю. H. (1999). The control law and performance of aero propulsive equipment. Beijing: National Defense Industry Press. 